\title{
EDITORIAL
}

\section{LA REVISTA CHILENA DE DERECHO CUMPLE 35 AÑOS}

El presente año 2009 nuestra publicación ha cumplido 35 años y hemos querido hacer mención y también conmemoración de este importante hito en el último número del año.

El tiempo transcurrido no solo importa el acopio efectivo de una vasta y rica gama de investigaciones jurídicas y aportes a la doctrina tanto nacional como internacional, comentarios de significativos fallos, recensiones sobre obras atractivas de las diversas especialidades del Derecho y notas sobre la contingencia jurídica a través de ensayos, crónicas y contrapuntos, sino y por sobre todo, un proyecto que se ha desarrollado en el tiempo y que ha significado un compromiso a largo plazo adquirido por la Facultad de Derecho de la Pontificia Universidad Católica de Chile ante la comunidad jurídica, el ámbito profesional de nuestros abogados, el desarrollo académico de la ciencia del Derecho y nuestro público lector interesado en aspectos legales, jurisprudenciales o pertenecientes a la literatura del área.

Ese proyecto ha dado importantes frutos: somos una revista de alto interés e impacto no solo entre los estudiantes y docentes de nuestra Universidad, sino del país; estamos indizados en importantes referentes como lo son SCielo, DIALNET, Scopus, Ebsco, Oceano, Latindex; hemos ido ampliando nuestra cobertura, tanto respecto de nuestros lectores como de los autores, pares evaluadores y miembros del Comité Editorial a importantes ámbitos jurídicos extranjeros y, podemos decirlo con orgullo, estamos trabajando dedicadamente para hacer la incorporación a ISI una realidad futura pero, confiamos, no distante.

Sin embargo, los aniversarios, además de servir de recuento de las etapas cumplidas y de los logros alcanzados, son un buena oportunidad para otras dos tareas a las que conferimos una gran importancia: determinar lo que será el Proyecto futuro, nuestras nuevas metas y desafíos, por una parte, y, por la otra, valorar y agradecer a las personas que con su trabajo, dedicación, esfuerzo y voluntad han sido los artífices de un producto material pero que conlleva una importante cuota de acuerdos, sueños, esfuerzos, incertidumbres y esperanzas.

Sean, en ese tenor, mis primeras palabras y mi reconocimiento más profundo a los directores de la Revista a través de su historia: maestros que, no satisfechos con la producción jurídica que ellos mismos hicieron en sus respectivas cátedras y foros, quisieron llevar el trabajo jurídico de otros autores a una difusión real y concreta, sentaron pautas de excelencia, posicionaron nuestra publicación y el nombre de la Universidad y de la Facultad ante la colectividad jurídica.

El trabajo de los directores ha sido complementado y engrandecido con el esfuerzo de sus equipos: los secretarios de redacción, siempre al lado del director en aquello que haga falta, con lealtad y sabiduría; los ayudantes, savia nueva que refresca nuestras 
líneas, nos dan alegrías y luces acerca del avance de las materias y del recambio de intereses y generaciones; las secretarias, que con abnegación y paciencia, con esfuerzo y con amor, concretizan mucho de lo que se idea y consiguen efectivamente que los planes sean realidades y los amigos encargados de nuestra edición y distribución, que nos han acompañado y hasta tolerado apuros, cambios, modificaciones y urgencias, con comprensión y con profesionalismo.

El ámbito netamente científico de la Revista ha gozado de un inmejorable grupo de académicos que han conformado su Comité Editorial, su Comité de Redacción y su grupo de árbitros, todos los cuales han prestigiado nuestra publicación, han establecido bases importantes de exigencia, seriedad e interés de nuestros artículos publicados y nos han ofrecido de manera constante su consejo y su experiencia.

Destacamos asimismo el gran apoyo que la edición de nuestra revista ha obtenido sin lugar a dudas, en lo interno, de parte de nuestros Decanos, autoridades de la Facultad y también miembros del Nivel Central de la Universidad, que han demostrado su interés y su voluntad de apoyo a la gestión de ella durante estos años. Y tan buena impronta se ha proyectado virtuosamente a nuestras relaciones con CONICYT y las demás entidades en que hemos tenido la oportunidad de incluir a nuestra Revista e indizarla.

Finalmente, y no por ello menos importantes, gracias a nuestros lectores, a nuestros críticos, a nuestros observadores, que sin elogios gratuitos y siempre con nobleza, nos consultan, nos comentan, nos siguen y nos motivan en una tarea constante y renovadora.

Del Proyecto 2010 les comentaremos pronto. Como un pequeño adelanto abrimos en esta oportunidad una nueva sección, dentro de Ensayos y Crónicas, dedicada a los Juristas Destacados y que, tal cual su nombre lo dice, está destinada a brindar unas páginas para que los grandes hombres y mujeres del Derecho nos aporten sus reflexiones sobre los temas de actualidad.

Y con ello los dejamos, pues este tiempo es de celebrar y de mirar hacia atrás con una mano en el corazón, satisfechos de haber podido hacer mucho de lo que quisimos y de haber sembrado lo necesario para seguir en la brecha con fortaleza y con ilusión.

Deseo a todos y a cada uno una hermosa Navidad y un Año Nuevo venturoso, en el que, como siempre, la Revista Chilena de Derecho seguirá estando con ustedes. 